\title{
Reflexões geográficas em tempos de pandemia
}

Reflexões geográficas em tempos de pandemia

Réflexions géographiques en temps de pandémie

Reflexiones geográficas en tiempos de pandemia

Geography reflections in times of pandemic

\section{Rogério Haesbaert}

\section{(2) OpenEdition}

Journals

Edição electrónica

URL: http://journals.openedition.org/espacoeconomia/11826

DOI: 10.4000/espacoeconomia.11826

ISSN: 2317-7837

Editora

Núcleo de Pesquisa Espaço \& Economia

Refêrencia eletrónica

Rogério Haesbaert, "Reflexões geográficas em tempos de pandemia », Espaço e Economia [Online], 18 | 2020, posto online no dia 17 abril 2020, consultado o 20 maio 2020. URL : http://

journals.openedition.org/espacoeconomia/11826 ; DOI : https://doi.org/10.4000/espacoeconomia 11826

Este documento foi criado de forma automática no dia 20 maio 2020.

(C) NUPEE 


\title{
Reflexões geográficas em tempos de pandemia
}

\author{
Reflexões geográficas em tempos de pandemia \\ Réflexions géographiques en temps de pandémie \\ Reflexiones geográficas en tiempos de pandemia \\ Geography reflections in times of pandemic
}

\section{Rogério Haesbaert}

1 A atual crise planetária desencadeada pela pandemia do Covid-19 (um tipo de coronavírus) está mergulhada em problemáticas de ordem geográfica. É fundamental avaliarmos nossas categorias à luz do que se passa pelo mundo. O território e os processos de des-reterritorialização nunca foram tão relevantes como agora, no combate à expansão do vírus.

2 Há um padrão recorrente nas medidas ditas de contenção promovidas por diferentes países, todas elas, em menor ou maior grau, voltadas para o controle da mobilidade daquele que já vinha sendo apontado, principalmente no pensamento decolonial feminista e indígena latino-americano, como nosso primeiro território, o corpoterritório - nunca dissociado, é claro, do domínio e apropriação territorial, maior ou menor, do seu entorno.

3 O controle (e docilização) dos corpos, sabemos bem, é empreitada antiga, e Michel Foucault foi o autor que melhor trabalhou a relação entre corpo e disciplina no mundo moderno. Ele propôs um interessante modelo que opunha as iniciativas de controle da lepra e da peste - o primeiro criando o que sugeri denominar "territórios de reclusão", com completo isolamento em relação ao restante da sociedade, e o segundo impondo o que chamei de "contenção territorial", tipo muro-barragem, onde o fechamento não é completo, é relativo e temporário, e no qual sempre existe alguma forma de ultrapassar a barreira que foi construída e entrar - ou fugir, dependendo da perspectiva. É esse o caso dos muros fronteiriços, de efeito mais simbólico que concreto, e que o migrante sempre se encarrega, de alguma forma, de contornar, descobrindo outro caminho. 
4 A globalização da pandemia impôs esse jogo entre reclusão ou confinamento e contenção ou barragem em múltiplas escalas. Num mundo moldado pelos territóriosrede onde os corpos se deslocam com muito mais rapidez e intensidade ao longo de circuitos que canalizam fluxos, malhas aéreas à frente, não é nada fácil restaurar os controles do tipo território-zona, em que se pode impedir a mobilidade dentro de áreas de menor ou maior amplitude, como sempre pretendeu fazer (cada vez com menos sucesso) o Estado-nação e suas unidades político-administrativas.

Pois são exatamente as tentativas de retorno a esse controle territorial zonal que se impuseram desde o início no combate à expansão do coronavírus. Como era de se esperar, nesse mundo neoliberal em que vivemos, quem até aqui obteve maior êxito no combate foi um dos Estados mais centralizados e autoritários, a China (há todo um debate sobre a especificidade de um "neoliberalismo chinês", "variegado" ou "de exceção", nos termos de Aihwa Ong, que não é possível tratar aqui). Como foi lá que teve início o processo e identificou-se o foco inicial - a grande metrópole de Wuhan - os esforços foram concentrados inicialmente no bloqueio completo dessa metrópole e na província de Hubei. Ter um único foco geográfico inicial de emissão ajudou muito - ao contrário de outros países, como os Estados Unidos, com focos emissores nos estados de Washington, Califórnia e Nova York.

6 Um fator que parece decisivo no caso do regime autoritário chinês diz respeito aos dispositivos de controle da informação e vigilância da população, acumulados ao longo do tempo e que têm sua base nos comitês de vizinhança que monitoram cada quarteirão ou pequeno grupo de famílias. Além disso, temos uma cultura disciplinar confuciana, a capacidade organizativa do sistema de saúde estatal e a prática generalizada do uso de máscaras pela população (inclusive há mais tempo, pela poluição).

70 processo de quarentena que, no caso chinês, alia dinâmicas de contenção e de confinamento, associado à própria natureza ditatorial do regime, foi muito mais severo que em outros países. As saídas de casa foram rigidamente controladas - inicialmente saída individual apenas a cada dois dias, depois confinamento total, somente permitida a recepção de alimentos e medicamentos por encomenda. No final, em Wuhan, policiais seguiam de casa em casa para checar as condições de saúde e, em caso de doença, os isolamentos forçados tornaram-se comuns. Reportou-se até mesmo a fiscalização do uso de máscaras através de drones, muito comuns como instrumento de vigilância pública. Dispositivos, digitais ou não (desde o antigo "hukou", ou cartão de residência), também já eram disseminados no controle da mobilidade da população.

8 Um controle fundamental que, este sim, atua diretamente sobre o que denominamos territórios-rede, é o dos fluxos aéreos internacionais. Wuhan é um grande hub aéreo com voos para diversos países da Ásia (Japão, Coreia do Sul, Taiwan, Tailândia, Emirados Árabes, Austrália, Singapura, Indonésia, Malásia...). Poderia se transformar num grande difusor da contaminação (o que em parte ocorreu). Muitos países, como o Brasil, tiveram um controle muito tardio da principal porta de entrada do vírus: os aeroportos internacionais. Optou-se primeiro pelo controle zonal de algumas fronteiras para só mais tarde atuar sobre o fluxo aéreo, provavelmente sob pressão do forte lobby das empresas aéreas e do setor de turismo. Diante da chamada "segunda onda" de contaminação, por aqueles que vêm de fora, a China voltou a endurecer o controle nos aeroportos, impondo quarentena de duas semanas para quem chega ao país.

9 A partir desse quadro mais empírico da dinâmica chinesa de contenção e confinamento, verifica-se o quanto se torna mais difícil para um país ocidental e, especialmente, de 
periferias como a América Latina e a África (onde o Covid-19 apenas começa a alcançar as áreas mais pobres), implementar o mesmo tipo e rigidez de controle territorial. Alguns questionam, frente ao relativo sucesso também de países como Coreia do Sul, Taiwan e Singapura, se a China não teria ido além do necessário. Uma medida comum a explicar o êxito desse bloco de países é, além da disciplina no confinamento e no distanciamento social (menos rígida fora da China), a detecção generalizada da presença do vírus entre as pessoas - já que o maior dilema é a disseminação do vírus por portadores assintomáticos. Detectá-la e isolar seus portadores é decisivo.

Pois é sobre esse isolamento que gostaria de me deter agora. o que vimos nos países europeus e americanos foi, inicialmente, uma crítica e rechaço (até por intelectuais conceituados como Giorgio Agamben) ao caráter excessivamente restritivo das medidas (como continua a pensar o presidente brasileiro, preocupado em primeiro lugar com a economia e jogando a responsabilidade das medidas de isolamento para os governadores estaduais). Logo depois, com o agravamento da situação, entretanto, muitos mudaram radicalmente de opinião e condenaram essas mesmas medidas por seu caráter incipiente, exigindo ainda maior rigor em sua aplicação. A principal delas é a rigidez da quarentena, hoje com amplo apoio popular entre nós ( $74 \%$ dos brasileiros, segundo pesquisa do instituto Datafolha), principalmente diante das cenas deploráveis vindas de países com sistemas de saúde considerados mais consistentes, como Itália e Espanha.

11 Uma característica básica dessa pandemia, de importante manifestação geográfica, é que ela, ao sair da China, começa no topo da pirâmide socioeconômica, entre as classes mais privilegiadas - basta ver o mapa de difusão inicial da pandemia numa metrópole periférica como o Rio de Janeiro, onde afeta inicialmente os bairros mais ricos, de onde chegaram os viajantes internacionais, primeiros portadores do vírus. A grande questão agora é que tipo de dinâmicas de contenção territorial são plausíveis em realidades "periférico-coloniais" como as do continente mais desigual do planeta, a América Latina. $\mathrm{O}$ vírus ainda não atingiu mas está começando a alcançar nossas favelas e villas miseria.

Entrará em ação, como já circulam informações, o aparato paramilitar das milícias a forçar os habitantes das favelas a permanecer em casa? Surtirá efeito propor o isolamento individual quando se sabe que, somente na área metropolitana do Rio de Janeiro, 300 mil domicílios só possuem um quarto para três pessoas ou mais e a maioria são casas geminadas, muitas vezes com corredores e cômodos partilhados?

Voltemos então ao nosso corpo-território: sem dúvida, no contexto da colonialidade do poder latino-americana, mais que discutir medidas de autocontenção territorial, barrando o acesso a favelas (como tentam fazer algumas associações de moradores em comunidades de morros que têm apenas uma, ou poucas entradas), precisamos pensar diretamente naqueles que, mais precarizados, só têm o corpo como território a ser defendido, como espaço sobre o qual ainda tentam manter algum controle - já que nem com um quarto individual em suas casas podem contar. Triste sina, diante de um vírus ardiloso: praticamente impossível "fechar", controlar sua entrada em nosso corpo quando não se dispõe nem do mínimo, a água e o sabão para a higiene pessoal, como ocorre agora em diversas favelas do Rio.

Sem pintar aqui o quadro sombrio que já se anuncia (como demonstram as cenas dos corpos depositados nas ruas de Guayaquil), gostaria de finalizar com uma breve reflexão teórica, entre as muitas evocadas neste texto. A contenção territorial que 
definimos (no livro "Viver no Limite") se refere aos macroprocessos socioeconômicos que acabam destinando aos grupos subalternos os territórios mais vulneráveis da cidade - periferias distantes, sem infraestrutura, encostas ecologicamente instáveis, várzeas inundáveis... De qualquer forma, eles aí estão apartados e, de certa forma, "contidos" como se fosse para não "contaminar" o resto da cidade. Agora, porém, trata-se de uma contenção às avessas. A pandemia, quem diria, veio subverter essa ideia de contenção dos subalternos pelos hegemônicos: são os próprios privilegiados que precisam se autoconter, confinar-se, pois foram eles que, inicialmente, no caso latino-americano, "carregaram o mal". Embora muitos tenham solicitado que suas empregadas domésticas ficassem em casa, inúmeros trabalhadores porteiros, faxineiros, garis, atendentes de supermercados, postos de gasolina e farmácias, sem falar nos profissionais de saúde - devem ter garantida sua mobilidade, ainda que sob condição de grande vulnerabilidade (como nos transportes públicos superlotados do Rio de Janeiro).

Os pouco esclarecidos, entretanto, dizem que o vírus "é democrático", que "atinge a todos por igual". O vírus não tem nada de democrático - primeiro, porque afeta de modo mais brutal os já mais fragilizados: idosos, enfermos, incapacitados e, a partir de agora, os mais pobres; segundo, porque, ao exigir para seu combate a autocontenção (ou reclusão temporária), ela só é realmente possível e segura para os mais ricos, que dispõem de condições para o distanciamento social e o isolamento.

Assim, temos muitas lições geográficas a aprender através dos distintos mecanismos de contenção territorial em função da pandemia. Aprendemos que, num mundo "informacional" de tantas tecnologias, ao final, o que realmente continua importando é o nosso corpo, o corpo-território enquanto condição última e inexorável de nossa existência. Seja o padrão da lepra, que nos confina, numa reclusão definitiva, seja o modelo da peste, com sua quarentena de contenção temporária, todos têm no controle dos corpos seu derradeiro alvo. Resta saber, por fim, quem de fato vai continuar exercendo controle sobre o conjunto da população e de seus corpos-territórios. Sem dúvida, uma outra biopolítica, centrada no afeto e no cuidado, urge construir. Uma advertência, apenas: a ilusão com o alegado êxito do modelo autoritário chinês. Ele oculta um padrão totalmente falido de crescimento e consumismo sem freios - além de um monitoramento individual irrestrito - que a pandemia poderia ajudar a destruir (uma utopia).

\section{BIBLIOGRAFIA}

AGAMBEN, G. 2020. O Estado de exceção provocado por uma emergência imotivada. Disponível em: http://www.ihu.unisinos.br/78-noticias/596584-o-estado-de-excecao-provocado-por-umaemergencia-imotivada (acessado em 15 mar. 2020)

FOUCAULT, M. 1984 (1975). Vigiar e Punir: nascimento da prisão. Petrópolis: Vozes. 
HAESBAERT, R. 2014. Viver no Limite: território e multi/transterritorialidade em temos de insegurança e contenção. Rio de Janeiro: Bertrand Brasil.

ONG, A. 2006. Neoliberalism as exception: mutations in citizenship and sovereignty. Durham e Londres: Duke University Press.

\section{RESUMOS}

A pandemia de Covid-19 e seu combate possuem uma clara e relevante dimensão geográfica. $\mathrm{O}$ texto se propõe a reavaliar certas categorias propostas para compreender os processos de des-reterritorialização, especialmente a reclusão ou confinamento e a contenção territorial. Assim, são interrogadas estratégias de contenção operadas desde a China às periferias urbanas na América Latina, sobretudo no Rio de Janeiro. No limite, o que está em jogo é o controle de nosso território mínimo, o corpo-território.

La pandémie de la Covid-19 et son combat possèdent une dimension géographique si claire que révélant. Le texte suivant se propose à réévaluer certaines catégories afin de comprendre les processus de dé-ré-territorialisation, surtout la réclusion ou le confinement et la contention territoriale. Ainsi, on remise en cause les stratégies de contention mises en pratique depuis la Chine aux périphéries urbaines dans l'Amérique Latine, notamment à Rio de Janeiro. A la limite, ce qui est en jeu, c'est le contrôle du notre territoire premier, le corps-territoire.

La pandemia de Covid-19 y su combate tienen una dimensión geográfica clara y relevante. El texto propone reevaluar ciertas categorías propuestas para comprender los procesos de des-reterritorialización, especialmente la reclusión o confinamiento y la contención territorial. Así, se cuestionan las estrategias de contención operadas desde China hasta las periferias urbanas de América Latina, especialmente en Río de Janeiro. En el límite, lo que está en juego es el control de nuestro territorio mínimo, el territorio del cuerpo.

The Covid-19 pandemic and the measures to fight against it have a clearly and relevant geographical dimension. In this way, this text aims to reconsider some categories proposed to understand the processes of de-re-territorialization, particularly reclusion or confinement and territorial contention. So we are put in question different strategies of contention from China to Latin America urban peripheries, most notably Rio de Janeiro. At the limit, what is at stake is the control of our minimum territory, the body-territory.

\section{ÍNDICE}

Mots-clés: Covid-19, contention territoriale, confinement, corps-territoire, biopolitique.

Keywords: Covid-19; territorial containment; confinement; territory-body, biopolitics.

Palavras-chave: Covid-19, contenção territorial, confinamento, corpo-território, biopolítica.

Palabras claves: Covid-19, contención territorial, confinamiento, cuerpo-territorio, biopolítica.

\section{AUTOR}

\section{ROGÉRIO HAESBAERT}

Programa de Pós-Graduação em Geografia, Universidade Federal Fluminense, rogergeo@uol.com.br 